\title{
Effects of neighboring organisms on the growth of three intertidal encrusting cheilostome bryozoans
}

\author{
Kanavillil Nandakumar*, Masao Tanaka** \\ Amakusa Marine Biological Laboratory, Kyushu University, Tomioka Kumamoto-ken 863-25, Japan
}

\begin{abstract}
The effects of neighboring organisms on the growth and mortality of 3 encrusting bryozoan species, Celleporaria aperta, Schizoporella serialis and Watersipora subovoidea, were studied on PVC panels suspended in an intertidal area of Tomioka Bay, Japan. A total of 24 isolated colonies of $C$. aperta (i.e. from which neighbors were experimentally removed) and 27 colonies with neighbors, 8 isolated colonies of $S$. serialis and 14 colonies with neighbors, and 6 isolated colonies of $W$. subovoidea and 6 colonies with neighbors were monitored during the experiment. In all, 11 species belonging to different taxa were identified as the neighbors. C. aperta, S. serialis and $W$. subovoidea growing in the midst of neighbors grew more slowly than did the corresponding isolated colonies. Of the 3 species grown in the midst of neighbors, $W$. subovoidea showed the fastest growth rate while $C$. aperta showed the slowest. Growth in $S$. serialis when with neighbors was inversely related to the size of the colony at the time of contact and directly related to the duration of contact (in days) with the neighbors, while no significant relationship was obtained between its growth and length of interface with the colonies of neighboring organisms. In the other 2 species, growth was not significantly related with the 3 factors mentioned above. Mortality rates were different among the 3 species. No mortality occurred in isolated colonies of any of the 3 species, nor in colonies of $W$. subovoidea grown with the neighboring organisms. In contrast, when with neighbors, nearly $15 \%$ and $7 \%$ of colonies of C. aperta and S. serialis died, respectively.
\end{abstract}

KEY WORDS: Cheilostome bryozoans - Isolated colonies - Mixed colonies - Neighbors - Growth rate

\section{INTRODUCTION}

Competition among sessile invertebrates under several environmental conditions has been widely studied (Connell 1961, Dayton 1971, Stebbing 1973, Jackson 1977, Osman 1977, Russ 1982, Lopez Gappa 1989, Myers 1990, Steneck et al. 1991). Growth of sessile invertebrates on a space-limited substratum could ultimately lead to competition for space (Underwood 1979, 1992) and/or for food (Buss 1979, Best \& Thorpe 1986, Peterson \& Black 1987, Okamura 1988, 1992). As suggested by Buss (1979) and Fréchette et al. (1992), the competition is influenced by 2 interdependent factors, food and space, and both of these play a significant role in determining the structure of species assem-

\footnotetext{
- Present address: Marine Corrosion and Materials Research Division, National Institute of Oceanography, PO Dona Paula, Goa, India

* Addressee for correspondence
}

blage in any shallow and coastal water habitats (Underwood 1979, 1992).

Though detailed information is available on the processes of competition amongst sessile invertebrates, very little information exists on the fine-scale effects of physical contact with neighboring organisms. Important works in this line include Lutaud (1983), Lidgard (1984), Harvell \& Padilla (1990), Harvell (1992) and Harvell \& Helling (1993). The neighboring organisms can, for instance, deplete local availability of food to the suspension feeding community by interfering with the feeding currents (Buss 1979, LaBarbera 1981, Okamura 1984, 1985, Best \& Thorpe 1986). They also affect growth rate, survival, shape and reproductive output of the sedentary organisms (Broom 1982, Peterson 1982, Okamura 1986, Peterson \& Beal 1989, Zajac et al. 1989, Romano 1990, Alino et al. 1992).

For this study, colonies were grown on artificial substrata without and with neighbors. Faster growth enables sessile invertebrates to occupy the maximal 
available space on a hard substratum in the shortest time. In a sessile invertebrate community, the rate at which a species grows is considered to be an important factor influencing its competitive superiority (Nandakumar et al. 1993). Species that can grow fast while in contact with neighbors might occupy a dominant position by overgrowing them.

In the present study, the effect of a heterogeneous assemblage on the growth of the 3 bryozoan species Celleporaria aperta, Schizoporella serialis and Watersipora subovoidea was examined. Of the 3 bryozoan species studied, W. subovoidea occupied a higher position in the competitive ranking of the sessile fouling community than the other 2 species (Nandakumar et al. 1993). There are no other major types of competitive mechanisms involved here than simple overgrowth over the neighboring organisms. We therefore hypothesize that while in contact with the neighboring organisms, the faster a species grows, the higher the competitive ability of that species is.

\section{MATERIALS AND METHODS}

This study was conducted in Tomioka Bay, southern Japan $\left(32^{\circ} 33^{\prime} \mathrm{N}, 130^{\circ} 01^{\prime} \mathrm{E}\right)$. A description of the study area is given in Nandakumar et al. (1993). The present study was carried out for a period of $4 \mathrm{mo}$ in winter (from 5 December 1991 to 31 March 1992) when the seawater temperature varied from 13.2 to $18.4^{\circ} \mathrm{C}$.

Experimental design and measurements. Sixteen plastic (PVC) panels, each measuring $12.5 \times 12.5 \times$ $0.3 \mathrm{~cm}$, were suspended $1 \mathrm{~m}$ below the water surface from a floating platform. The surfaces of the panels were roughened with sandpaper. A number of colonies of Celleporaria aperta, Schizoporella serialis and Watersipora subovoidea along with other fouling organisms settled on the panels within $6 \mathrm{wk}$. The neighbors belonged to 4 taxa/groups: algae, polychaetes, bryozoans, and ascidians. Panels were brought back to the laboratory and kept in running seawater to prepare experimental colonies. To obtain solitary colonies on the panels (hereafter referred to as isolated colonies), all the neighboring organisms were removed using a scalpel. To prepare colonies with their neighbors (hereafter referred to as mixed), all organisms except those in a $3 \mathrm{~cm}$ diameter area around the target colony/colonies were removed. This limited fouling settlement around each colony, restricted the encroachment of other fouling organisms to the experimental systems and prevented large variability in size among the competing species. The mixed and isolated colonies were grown together on the same panel surfaces.

In these experiments, 24 isolated and 27 mixed colonies of Celleporaria aperta, 8 isolated and 14 mixed colonies of Schizoporella serialis and 6 isolated and 6 mixed colonies of Watersipora subovoidea were monitored. The positions of all colonies were marked using a numbered grid ( $1 \mathrm{~cm}^{2}$ dot interval) on a transparent acrylic sheet the same size as the panel. This was laid over the panel to fix the exact positions of the colonies during observations. Panels were put in a tray containing seawater while the colonies were traced under a stereomicroscope. The panels were observed 5 times during the study at about $2 \mathrm{wk}$ intervals after suspension $(42,56,70,82$ and $96 \mathrm{~d})$. A list of the neighboring species and the type of interactions involved among these and the 3 bryozoan species is given in Fig. 1.

During each observation, newly settled organisms were removed using a scalpel so as to keep the experimental design intact. The fresh settlement mainly included microalgae or microscopic forms of the macroalgae, juvenile forms of fouling organisms and organic matter. Each observation involved retrieval of the panels, removal of fresh settlers, tracing colonies and their contacting neighbors and returning the panels to the site. Mortality was also noted during each observation which took about 36 to 48 h to complete.

From the sketches of the experimental panels the areas of colonies were calculated using a digitizer. From the changes in area, the growth (in area) of each colony was calculated. The length of contact or interface of each colony with its neighbors (i.e. the length of contacting edge) was measured at the final observation and expressed as the percentage of perimeter of the colony. This is a measure of intensity of overgrowth. The growth rate is defined as the increase in area of the bryozoan colonies, since they are encrusting in nature.

The thickness at the growing margin 10.5 to $1 \mathrm{~mm}$ inside the perimeter) was measured at the end of the

CS AC ES SW BC CA SS WS PJ DT BS
\begin{tabular}{|l|l|l|l|l|l|l|l|l|l|l|}
\hline NS & & - & - & NS & FR & $\uparrow$ & $\uparrow$ & NS & $\uparrow$ & $\uparrow$ \\
\hline$N S$ & & - & - & NS & - & $F$ & $\uparrow$ & NS & $\uparrow$ & NS \\
\hline NS & - & - & NS & NS & - & - & OG & NS & NS & - \\
\hline
\end{tabular}

Fig. 1 Results of interactions between the neighbors (listed above the matrix) and the 3 bryozoan species (left side of the matrix). Arrows indicate the dominant winner (after $\chi^{2}$ test). NS: no significant winner; FR: fusion, but forms erected ridge; $F$ : fusion; OG: overgrowth by either colony of the same species; blank spaces: no interaction observed (data source: Nandakumar et al. 1993, Nandakumar unpubl data). Algae: Colpomenia sinuosa, CS; Enteromorpha sp., ES; algal complex, AC. Polychaeta: serpulid worms, SW. Bryozoa: Bugula californica, BC, Celleporana apertd, CA, Schizoporella serralis, SS; Watersipora subovoidea, WS. Ascidia: Perophora japonica, PJi Diplosoma mitsukuni, DT; Botryllus schlosseri, BS 
experiment using a micrometer attached to the focusing cylinder of a microscope $( \pm 2 \mu \mathrm{m})$. By initially focusing on the bare plate and then on the growing margin, the difference in readings could be taken as the thickness of the margin of the colonies.

During this study, the growth rate of bryozoan colonies was calculated using the formula

$$
S=\mathrm{e}^{b t+a}
$$

where $S$ is the size of the colony, $\mathrm{e}^{\mathrm{a}}$ is the initial size, $\mathrm{e}^{t}$ is time in days and $\mathrm{e}^{b}$ is the increase in colony size per day or growth rate.

Calculation and statistics. Data on sizes of isolated and mixed colonies were linearized by log transformation. Regression coefficients of log colony size vs time for growth of each colony were calculated. Thus each colony provided single $a$ and $b$ values or intercept and slope, respectively. Only the slopes (= growth rates, $b$ ) were compared because the intercept depends on the exact time of contact between the test colonies and the neighboring species. This was not known (subject to an error of a sampling interval).

The $b$ values of the isolated colonies of each species were compared with those of the mixed colonies of the respective species using an unpaired 1 -tail $t$-test (Sokal $\&$ Rohlf 1981). The mean reduction in growth rate of the mixed colonies as compared to their isolated counterparts was calculated from the ratio $e^{b}$ mixed $/ \mathrm{e}^{b}$ isolated. In order to compare the growth rates (b) of the 3 species, a $t$-test was done on the $b$ values (mixed and isolated colonies of the 3 species compared separately). In addition, the relationship between growth rate of the mixed colonies and their size at the time of contact, duration of contact and final length of interface with neighbors were tested using simple regression analysis.

\section{RESULTS}

\section{Vertical relief}

Among the 3 cheilostome bryozoan species studied here, Celleporaria aperta was found to produce axial buds while the 2 other species, Schizoporella serialis and Watersipora subovoidea, produced only frontal buds. Thus the mixed $C$. aperta colonies showed a linear increase in thickness with area $\left(r^{2}=0.861, p<\right.$ $0.001, \mathrm{n}=27$ ). However, the thickness of control (isolated) colonies $(1.202 \pm 0.24 \mathrm{~mm})$ was not significantly different from the mixed colonies $(1.135 \pm$ $0.23 \mathrm{~mm}$ ) (ANOVA, $F_{1.29}=0.0796, \mathrm{p}=0.38$ ). In the study area, the average thickness of $W$. subovoidea and S. serialis was $1.48 \pm 0.27$ and $1.20 \pm 0.30 \mathrm{~mm}$, respectively.

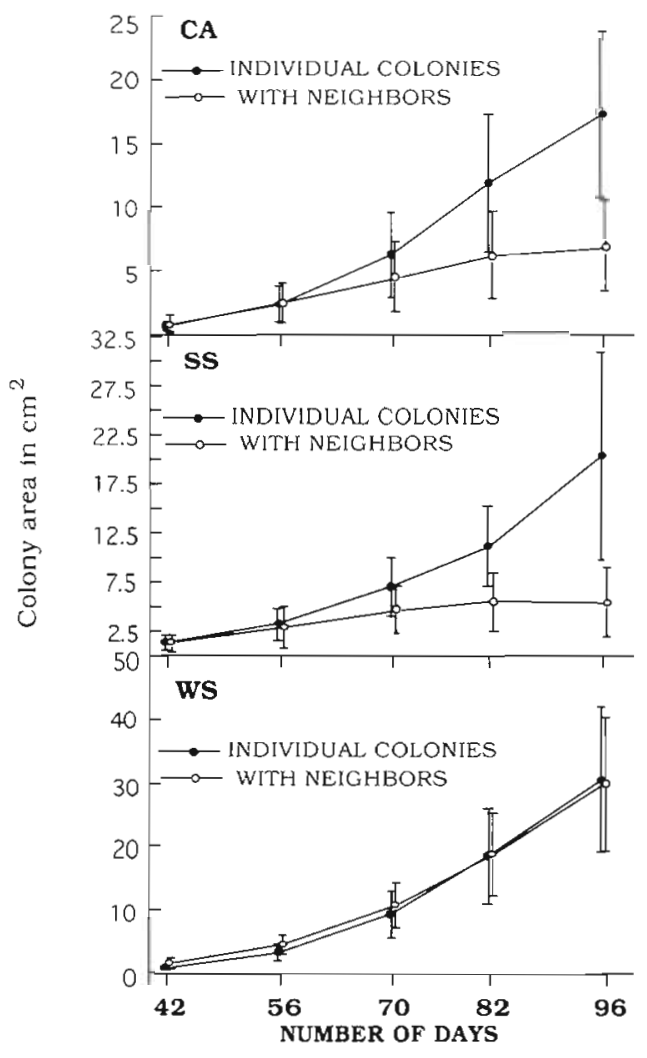

Fig. 2. Average growth ( $\pm \mathrm{SD}$, vertical bars) of bryozoan colonies grown with and without neighbors during the experiment. CA: Celleporaria aperta; SS: Schizoporella serialis; WS: Watersipora subovoidea

The average growths of isolated and mixed colonies with time are plotted in Fig. 2. It is clear that the growth in isolated colonies of Celleporaria aperta and Schizoporella serialis was significantly higher than their mixed colonies. But, in Watersipora subovoidea, such a significant difference between isolated and mixed colonies was not observed in the graphs. The mean growth rates of 3 species while isolated and mixed were $0.069 \pm 0.0151$ and $0.0195 \pm 0.0101 \mathrm{~mm}^{2}$ $\mathrm{d}^{-1}$ (C. aperta), $0.0538 \pm 0.0142$ and $0.0214 \pm 0.0185$ $\mathrm{mm}^{2} \mathrm{~d}^{-1}$ (S. serialis) and $0.0657 \pm 0.058$ and $0.0465 \pm$ $0.0057 \mathrm{~mm}^{2} \mathrm{~d}^{-1}$ (W. subovoidea). The $t$-test between the $b$ values of isolated and mixed colonies of the 3 species showed significant difference $(t=13.57, \mathrm{p}<$ $0.001 ; t=4.27, \mathrm{p}<0.001$ and $t=5.78, \mathrm{p}<0.001$ for $C$. aperta, $S$. serialis and $W$. subovoidea, respectively). However, the mean reduction in growth among the mixed as compared to the isolated colonies of the 3 species followed the order $W$. subovoidea $(29.22 \%)>$ S. serialis $(60.22 \%)>$ C. aperta $(70.28 \%)$.

The comparison of growth rates of the 3 species while isolated and mixed gave the following results. While there were significant differences between the 
growth rates of isolated colonies of Watersipora subovoidea and Schizoporella serialis ( $t$-test, $p<0.05$ ) and $S$ serialis and Celleporaria aperta ( $t$-test, $p<0.05$ ), no significant difference was detected between the growth rates of $W$. subovoidea and $C$. aperta ( $t$-test, $p$ $=0.36$ ). But, for the mixed colonies, while there were significant differences between $W$. subovoidea and $S$. serialis and $W$. subovoidea and $C$. aperta ( $t$-test, $\mathrm{p}<$ $0.001)$, no significant difference was detected between $S$. serialis and $C$. aperta ( $t$-test, $\mathrm{p}=0.14$ ).

The relationship between the growth rates and sizes of test colonies at the time of contact with neighbors ( \pm $10 \mathrm{~d}, 1$ sampling interval), their durations of contacts and the final lengths of interfaces with the neighbors are given in Fig. 3 . While the colony sizes at the time of contact with neighbors and the lengths of interfaces between the neighboring organisms were found to have a trend of inverse relationship with growth rate, the duration of contact with the neighbors had no significant adverse effects on growth rates (Fig. 3). However, in Schizoporella serialis statistically significant relationships were observed between growth rate and the colony size at the time of contact and duration of contact (see Fig. 3 for $r^{2}$ and $p$ values).

Mortality among the mixed colonies during the experiment was minimal for all 3 species studied.
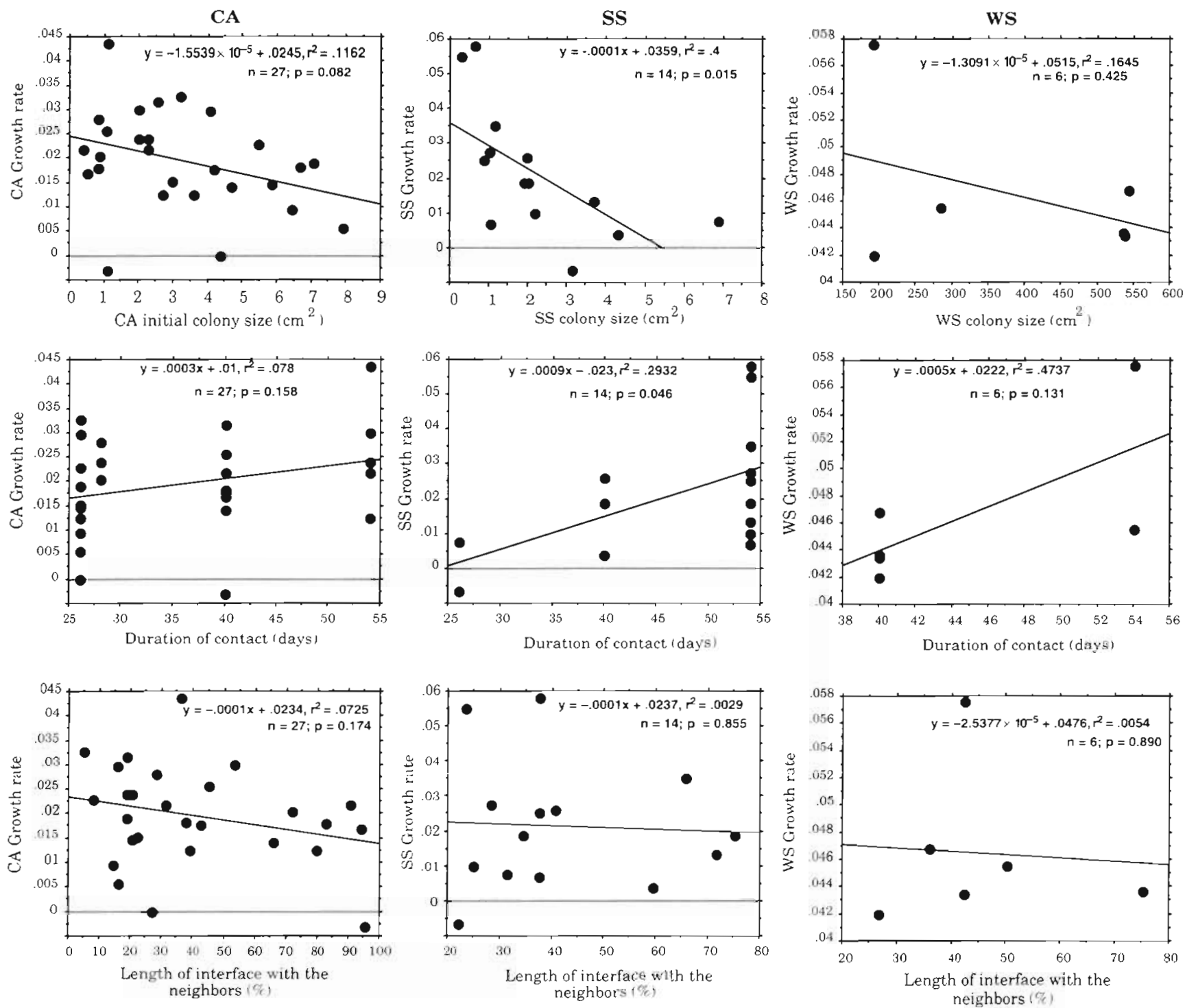

Fig. 3. Regression analysis of the relationship between the growth rates of 3 bryozoan species (CA: Celleporaria aperta; SS: Schizoporella serialis; WS: Watersipora subovoidea) and their initial colony sizes at the time of contact with the neighbors, duration of contact and length of interface (as \% of colony permeter) with the neighboring organisms. Each column corresponds to the bryozoan species abbreviated at the top 
Table 1. Mortality of the 3 bryozoan species during the experiments. A: control colonies grown individually; B: colonies grown with neighbors; $N$ : initial number of colonies

\begin{tabular}{|c|c|c|c|c|c|c|c|c|c|}
\hline \multirow[t]{2}{*}{ Species } & \multirow[t]{2}{*}{ Type } & \multirow[t]{2}{*}{$\mathrm{N}$} & \multicolumn{5}{|c|}{$\begin{array}{l}\text { No. of colonies which died during } \\
\text { observation period of: }\end{array}$} & \multirow[t]{2}{*}{ Total } & \multirow[t]{2}{*}{$\%$} \\
\hline & & & $42 d$ & $56 \mathrm{~d}$ & $70 \mathrm{~d}$ & $82 \mathrm{~d}$ & $96 \mathrm{~d}$ & & \\
\hline \multirow{2}{*}{ Celleporaria aperta } & A & 21 & 0 & 0 & 0 & 0 & 0 & 0 & \\
\hline & $\mathrm{B}$ & 27 & 0 & 0 & 0 & 2 & 2 & 4 & 14.8 \\
\hline \multirow[t]{2}{*}{ Schizoporella serialis } & A & 6 & 0 & 0 & 0 & 0 & 0 & 0 & \\
\hline & B & 14 & 0 & 0 & 0 & 0 & 1 & 1 & 7.1 \\
\hline \multirow[t]{2}{*}{ Watersipora subovoidea } & A & 6 & 0 & 0 & 0 & 0 & 0 & 0 & \\
\hline & $\mathrm{B}$ & 6 & 0 & 0 & 0 & 0 & 0 & 0 & 0 \\
\hline
\end{tabular}

However, the data showed that the death of test colonies occurred towards the end of the experiment (4th and 5th observations; Table 1), i.e. after experiencing a prolonged contact with neighbors. A total mortality of $14.8 \%$ was observed in the Celleporaria aperta colonies while $7.1 \%$ mortality was observed in the colonies of Schizoporella serialis. No mortality was observed in the mixed colonies of Watersipora subovoidea or in isolated colonies of the 3 species.

\section{DISCUSSION}

Among colonial organisms living next to other species, growth is reported to be notably retarded (Okamura 1992). However, reports suggesting enhanced survival of colonies with increasing density of conspecifics in bryozoans are also available (Buss 1981, Keough 1986). Buss (1990) mentioned that the effect of competition is very evident when one of the competing colonies ceases to grow or dies.

In this study, the 2 species of bryozoans (Celleporaria aperta and Schizoporella serialis) living in association with the neighbors showed significant reduction in growth as compared to their isolated counterparts (Fig. 2 and $t$-test results). The third bryozoan species, Watersipora subovoidea, was found to be least affected by the contact of neighbors (Fig. 2). Sebens (1986) and Nandakumar et al. (1993) observed that the growth rate of a species plays an important role in the success of interspecific competition. Among 3 species studied here, $W$. subovoidea showed significantly better growth than the other 2 species while grown with neighbors. In an earlier study on interspecific competition among sessile organisms from the same study area, $W$. subovoidea was shown to occupy a higher rank in the competitive hierarchy than the other 2 species (Nandakumar et al. 1993). These results thus bring out the importance of growth rate in the competitive success of these 3 species and agrees well with the hypothesis tested during the study.

Reduced growth observed in the bryozoan colonies while in contact with neighbors could be due to the physical contact of the neighboring organisms resulting in the death of the marginal zooids (Karande \& Udhayakumar 1992), the production of chemical toxins by the neighboring ascidians and sponges (Jackson \& Buss 1975), or the interference in feeding current (Okamura \& Doolan 1993). In the present study, since the area of fouling settlement around the test colonies was limited to $3 \mathrm{~cm}$ diameter, most of the neighboring species appearing within this area made physical contact with the test organisms. The reduced growth rates observed among the mixed colonies was thus attributed to the physical contact with the neighboring organisms.

The cheilostome bryozoan Membranepora membranacea $\mathrm{L}$. has been well studied for the finer changes occurring at the growing margins of colonies by Harvell \& Padilla (1990), Harvell et al. (1990), Harvell (1992) and Harvell \& Helling (1993). Harvell \& Helling (1993) stated that reproduction is induced at the damaged sites of colonies. This behavior, however, was not found to be uniform, and they concluded that reproduction depended on the configurations of the damaged edges. They also reported enhanced reproduction rates at the contact points with conspecifics.

In the present study, bryozoans living in contact with their neighbors showed a significant reduction in growth. The growth rate showed a negative relationship with the length of interface and size of colonies at the time of contact with the neighboring organisms (Fig. 3). However, the duration of contact showed a positive relationship with the growth rate among the 3 species. The results of these analyses show one clear point, i.e. that the length of interface and the colony size at the time of contact are the more important factors influencing growth rate in these 3 species of bryo- 
zoans than the duration of contact with the neighbors. The importance of colony size on the competitive success of sessile organisms has been well documented by Buss (1980).

In short, the results of this experiments showed that similar groups of neighboring organisms caused effects of varying extents on the 3 bryozoan species. That is, in spite of having close similarities in the nature of growth (all 3 are encrusting cheilostomates), the effect of similar groups of neighbors differed considerably.

Earlier studies on bryozoans reported incidence of high mortality in crowded situations (Rubin 1985, Harvell et al. 1990, Karande \& Udhayakumar 1992). In the present study, however, more mortality was observed among the competitively inferior species Celleporaria aperta and Schizoporella serialis towards the end of the experiment (Table 1). Colony mortality increased with the duration of contact with the neighbors (Table 1). This again leads us to believe that the longer the duration of contact with the neighbors, the more severe its effect on a colony's longevity.

Acknowledgements. We are grateful to Prof. Taiji Kikuchi, Amakusa Marine Biological Laboratory, for the advice and helpful suggestions during the course of this study. Prof. S. Mawatari, Hokkaido University, kindly identified the bryozoan species. Comments of Drs A. A. Karande, S. C. Pennings and $Y$ Takada and 2 anonymous referees are gratefully acknowledged. Comments of Dr A. J. Underwood on the sta. tistical methods were very useful. The first author acknowledges the Ministry of Science and Culture, Japan, for the financial support. This is Amakusa Marine Biological Laboratory Contribution No. 379.

\section{LITERATURE CITED}

Alino, P. M., Sammarco, P. W., Coll, J. C. (1992). Competitive strategies in soft corals (Coelenterata, Octocorallia). IV Environmentally induced reversals in competitive superiority. Mar. Ecol. Prog. Ser. 81: 129-145

Best, M. A., Thorpe, J. P. (1986). Feeding-current interactions and competition for food among the bryozoan epiphytes of Fucus serratus. Mar. Biol. 93: 371-375

Broom, M. J. (1982). Analysis of the growth of Anadara granosa (Bivalvia: Acridae) in natural, artificially seeded and experimental populations. Mar. Ecol. Prog. Ser. 9: 69-79

Buss, L. W. (1979). Bryozoan overgrowth interactions: the interdependence of competition for space and food. Nature 81: 475-477

Buss, L. W. (1980). Competitive intransitivity and size frequency distributions of interacting populations. Proc natl Acad. Sci. U.S.A. 77: 5255-5259

Buss, L. W. (1981). Group living, competition and the evolution of cooperation in a sessile invertebrate. Science 213 $1012-1014$

Buss, L. W. (1990). Competition within and between encrusting clonal invertebrates. TREE 5: 352-356

Connel.., J. H. (1.961). The influence of interspecific competition and other factors on the distribution of the barnacle Chthamalus stellatus. Ecology 42: 710-723
Dayton, P. K. (1971). Competition, disturbance and community organization: the provision and subsequent utilization of space in a rocky intertidal community. Ecol. Monogr. 41: $351-389$

Fréchette, M., Aitken, A. E., Pagé, L. (1992), Interdependence of food and space limitation of a benthic suspension feeder: consequences for self-thinning relationships. Mar. Ecol. Prog. Ser. 83: 55-62

Harvell, C. D. (1992). Inducible defenses and allocation shifts in a marine bryozoan. Ecology 73: 1567-1576

Harvell, C. D., Caswell, H., Simpson, P. (1990). Density effects in a colonial monoculture: experimental studies with a marine bryozoan (Membranepora membranacea L.). Oecologia 82: 227-237

Harvell, C. D., Helling, R. (1993). Experimental induction of localized reproduction in a marine bryozoan. Biol. Bull. 184: $286-295$

Harvell, C. D., Padilla, D. K. (1990). Inducible morphology, heterochrony, and size hierarchies in a colonial invertebrate monoculture. Proc. natl Acad. Sci. U.S.A. 87: $508-512$

Jackson, J. B. C. (1977). Competition on marine hard substrata: the adaptive significance of solitary and colonial strategies. A.m. Nat. 111 743-767

Jackson, J. B. C., Buss, L. W. (1975). Allelopathy and spatial competition among coral reef invertebrates. Proc. natl Acad. Sci. U.S.A. 72: $5160-5163$

Karande, A. A., Udhayakumar, M. (1992). Consequences of crowding on life-histories of cheilostome bryozoans in Bombay waters. Ind. J. mar. Sci. 21. 133-136

Keough, M. J. (1986). The distribution of a bryozoan on seagrass blades: settlement, growth and mortality. Ecology 67: $846-857$

LaBarbera, M. (1981). Water flow patterns in and around three species of articulate branchiopods. J. exp. mar. Biol. Ecol. 55: 185-206

Lidgard, S. (1984). Zooid and colony growth in encrusting cheilostome bryozoans. Paleontology 28: 255-291

Lopez Gappa, J. J. (1989). Overgrowth competition in an assemblage of encrusting bryozoans settled on artificial substrata. Mar. Ecol. Prog. Ser. 51: 121-130

Lutaud, G. (1983). Autozooid morphogenesis in anascan cheilostomes. In: Robison, R. A. (ed.) Treatise on invertebrate paleontology, Part B, Bryozoa (revised). University of Kansas Press and Geological Society of America, Lawrence, p. 208-237

Myers, P. E. (1990). Space versus other limiting resources for a colonial tunicate, Botrylloides leachii (Savigny), on fouling plates. J. exp. mar. Bıol. Ecol 141:47-52

Nandakumar, K. Tanaka, M., Kikuchi, T (1993). Interspecific competition among fouling organisms at Tomioka Bay, Japan. Mar. Ecol. Prog. Ser. 94: 43-50

Okamura, B. (1984). The effects of ambient flow velocity, colony size and upstream colonies on the feeding success of Bryozoa. I. Bugula stolonifera Ryland, an arborescent species. J. exp mar. Biol. Ecol. 83: 179-193

Okamura, B. (1985). The effects of ambient flow velocity, colony size and upstream colonies on the feeding success of Bryozoa. II. Conopeum reticulatum (Linnaeus), an encrusting species. J. exp. mar. Biol. Ecol. 89: 69-80

Okamura, B. (1986). Group living and the effects of spatial position in aggregations of Mytilus edulıs. Oecologia 69: 341-347

Okamura, B. (1988). The influence of neighbors on the feeding of an epifaunal bryozoan. J. exp. mar. Biol. Ecol. 120: $105-123$

Okamura, B. (1992). Microhabitat variation and patterns of 
colony growth and feeding in a marine bryozoan. Ecology 73: $1502-1513$

Okamura, B., Doolan, L. A. (1993). Patterns of suspension feeding in the fresh water bryozoan Plumatella repens. Biol. Bull. 184: 52-56

Osman, R. W. (1977). The establishment and development of a marine epifaunal community. Ecol. Monogr. 47: 37-63

Peterson, C. H. (1982). The importance of predation and intraand interspecific competition in the population biology of two infaunal suspension feeding bivalves, Protothaca staminea and Chione undatella. Ecol. Monogr. 52: 437-475

Peterson, C. H., Beal, B. F. (1989). Bivalve growth and higher order interactions: importance of density, site and time. Ecology 70: 1390-1404

Peterson, C. H., Black, R. (1987). Resource depletion by active suspension feeders on tidal flats: influence of local density and tidal elevation. Limnol. Oceanogr. 32: 143-166

Romano, S. L. (1990). Long-term effects of interspecific aggression on growth of the reef-building corals Cyphastrea ocellina (Dana) and Pocillopora damicornis (Linnaeus). J. exp. mar. Biol. Ecol. 140: 135-146

Rubin, J. A. (1985). Mortality and avoidance of competitive overgrowth in encrusting bryozoa. Mar. Ecol. Prog. Ser. 23: $291-299$

Russ, G. R. (1982). Overgrowth in a marine epifaunal commu-

This article was submitted to the editor nity: competitive hierarches and competitive networks. Oecologia 53: 12-19

Sebens, K. P. (1986). Spatial relationships among encrusting marine organisms in the New England subtidal zone. Ecol. Monogr. 56: 73-96

Sokal, R. R., Rohlf, F. J. (1981). Biometry, 2nd edn. W. H. Freeman \& Co., New York, p. 859

Stebbing, A. R. D. (1973). Competition for space between the epiphytes of Fucus serratus L. J. mar. biol. Ass. U.K. 53: $247-261$

Steneck, R. S., Hacket, S. D., Dethier, M. N. (1991). Mechanisms of competitive dominance between crustose coralline algae: an herbivore-mediated competitive reversal. Ecology 72: 938-950

Underwood, A. J. (1979). The ecology of intertidal gastropods Adv. mar. Biol 16: 111-210

Underwood, A. J (1992). Competition and marine plantanimal interactions. In: John, D. M., Hawkins, S. J., Price, J. H. (eds.) Plant animal interactions in the marine benthos. Systematic Association special volume No. 46, Clarendon Press, Oxford, p. 443-475

Zajac, R. N., Whitlach, R. B., Osman, R. W. (1989). Effects of inter-specific density and food supply on survivorship and growth of newly settled benthos. Mar. Ecol. Prog. Ser. 56: $127-132$

Manuscript first received: December 27, 1993

Revised version accepted: August 19, 1994 